\title{
Annexe 4 - Lucil, un succès commercial : quels enseignements pour l'institution éducative
}

Contribution de Véronique LECLERCQ - 21 mars 1992

Véronique Leclercq

\section{(2) OpenEdition}

\section{Journals}

Édition électronique

URL : http://journals.openedition.org/edc/2737

DOI : $10.4000 /$ edc. 2737

ISSN : 2101-0366

Éditeur

Université Lille-3

Édition imprimée

Date de publication : 1 mai 1993

Pagination : 105-106

ISSN : 1270-6841

Référence électronique

Véronique Leclercq, « Annexe 4 - Lucil, un succès commercial : quels enseignements pour l'institution éducative », Études de communication [En ligne], 14 | 1993, mis en ligne le 02 janvier 2012, consulté le 05 mai 2019. URL : http://journals.openedition.org/edc/2737 ; DOI : 10.4000/edc.2737

Ce document a été généré automatiquement le 5 mai 2019.

(C) Tous droits réservés 


\title{
Annexe 4 - Lucil, un succès commercial : quels enseignements pour l'institution éducative
}

Contribution de Véronique LECLERCQ - 21 mars 1992

\author{
Véronique Leclercq
}

Le produit LUCIL (Lutte Contre l'Illettrisme) est le résultat d'une collaboration entre le département "Formations de base et mise à niveau » du CUEEP et "Vendôme-Formation ", une petite société informatique filiale de l'UAP, spécialisée dans la création de didacticiels à des fins de formation interne à l'UAP. C'est donc la mise en commun d'une compétence pédagogique et d'un savoir-faire informatique qui a permis de concevoir et de réaliser de 1985 à 1987 un ensemble comprenant un didacticiel (de type fermé), des fiches pédagogiques pour les apprenants et un guide d'utilisation pour le formateur.

3 Cette expérience, dont il faut garder en tête le caractère précurseur, a servi de révélateur à un choc de logiques:

- dans la phase de conception-réalisation, les cultures et les modes d'organisation du travail des deux partenaires ont posé problème. Les informaticiens de Vendôme-Formation avaient l'habitude de travailler en " circuit fermé " sur des produits destinés à un public qualifié, sans qu'il y ait d'interaction avec les futurs utilisateurs. Leur priorité était le respect des obligations de production et des impératifs de délai. Si les formateurs du CUEEP ont ainsi été amenés à être plus rigoureux pour le respect des échéances, ils ont cependant dû lutter pied à pied pour qu'il soit tenu compte du temps propre à une expérimentation pédagogique, et pour que des modifications puissent être apportées au didacticiel ;

- dans la phase de commercialisation, le sentiment qui a prévalu chez les formateurs était que cette dernière venait en supplément, et que le bénéfice pour l'institution était d'abord la reconnaissance de sa compétence et de sa capacité d'innovation dans le domaine de l'illettrisme - ce à quoi le produit a effectivement contribué. Dès lors, il leur semblait naturel de le diffuser largement, $y$ compris sous forme de copies gratuites, ou dans des réseaux d'échanges mutualisés. Pour la société 
Vendôme-formation, chargée de la tâche de commercialisation, il s'agissait de vendre un produit informatique comme un autre : la dimension "service " lui échappait totalement.

4 Tirant les leçons de cette expérience, le CUEEP a décidé à l'avenir d'assurer seul la " maîtrise d'ouvrage ", d'internaliser au maximum la réalisation et de ne sous-traiter qu'à des sociétés proches. Quant à la société Vendôme-Formation, on peut s'interroger sur les motifs qui ont pu la pousser, de fait à perdre de l'argent plus qu'à en gagner, en collaborant avec un organisme public. Les réponses à cette interrogation passent sans doute par une analyse des stratégies d'internalisation/externalisation, d'hybridation des savoir-faire, à l'intersection du public et du privé.

\section{AUTEUR}

\section{VÉRONIQUE LECLERCQ}

Véronique LECLERCQ, Maître de Conférences au Centre Université Economie d'Éducation Permanente (CUEEP) de l'Université de Lille 1, et co-auteur du produit. 